\title{
Nicotine Blocks Brain Estrogen Synthase (Aromatase): In Vivo Positron Emission Tomography Studies in Female Baboons
}

\section{Citation}

Biegon, Anat, Sung-Won Kim, Jean Logan, Jacob M. Hooker, Lisa Muench, and Joanna S. Fowler. 2010. Nicotine blocks brain estrogen synthase (aromatase): In vivo positron emission tomography studies in female baboons. Biological Psychiatry 67(8): 774-777.

\section{Published Version}

doi:10.1016/j.biopsych.2010.01.004

\section{Permanent link}

http://nrs.harvard.edu/urn-3:HUL.InstRepos:12111433

\section{Terms of Use}

This article was downloaded from Harvard University's DASH repository, and is made available under the terms and conditions applicable to Other Posted Material, as set forth at http:// nrs.harvard.edu/urn-3:HUL.InstRepos:dash.current.terms-of-use\#LAA

\section{Share Your Story}

The Harvard community has made this article openly available.

Please share how this access benefits you. Submit a story.

\section{Accessibility}




\title{
Nicotine Blocks Brain Estrogen Synthase (Aromatase): In Vivo Positron Emission Tomography Studies in Female Baboons
}

\author{
Anat Biegon, Sung-Won Kim, Jean Logan, Jacob M. Hooker, Lisa Muench, and Joanna S. \\ Fowler \\ From the Brookhaven National Laboratory (AB, S-WK, JL, JMH, LM, JSF), Upton, New York; and \\ the National Institute on Alcohol Abuse and Alcoholism (S-WK, LM), Bethesda, Maryland
}

\begin{abstract}
Background-Cigarette smoking and nicotine have complex effects on human physiology and behavior, including some effects similar to those elicited by inhibition of aromatase, the last enzyme in estrogen biosynthesis. We report the first in vivo primate study to determine whether there is a direct effect of nicotine administration on brain aromatase.
\end{abstract}

Methods-Brain aromatase availability was examined with positron emission tomography and the selective aromatase inhibitor $\left[{ }^{11} \mathrm{C}\right]$ vorozole in six baboons before and after exposure to IV nicotine at .015 and $.03 \mathrm{mg} / \mathrm{kg}$.

Results-Nicotine administration produced significant, dose-dependent reductions in $\left[{ }^{11} \mathrm{C}\right]$ vorozole binding. The amygdala and preoptic area showed the largest reductions. Plasma levels of nicotine and its major metabolite cotinine were similar to those found in cigarette smokers.

Conclusions-Nicotine interacts in vivo with primate brain aromatase in regions involved in mood, aggression, and sexual behavior.

\section{Keywords}

Amygdala; CYP19; extragonadal estrogen; imaging; smoking; vorozole

Exposure to nicotine from cigarette smoke produces diverse behavioral and physiological effects-including changes in cognition, anxiety, and aggression-which are mostly explained by its interaction with nicotinic acetylcholine receptors (1). Some of the effects of nicotine, including its rewarding properties, seem to be modulated by sex and ovarian hormones in humans as well as rodents $(2,3)$. Furthermore, women who smoke cigarettes reach menopause at an earlier age than nonsmoking women and are more likely to develop osteoporosis and have lower plasma levels of the female sex hormone estrogen (4-6). The latter observations inspired several studies of nicotine and other tobacco constituents as direct inhibitors of estrogen synthesis $(7,8)$. The key enzyme in estrogen biosynthesis is aromatase (Cyp19, estrogen synthase), which catalyzes the last step of estrogen biosynthesis, aromatizing the A ring of androgens (e.g., androstenedione and testosterone) to estrone and $17 \beta$-estradiol respectively (9). Nicotine, its major metabolite cotinine, and other tobacco alkaloids were indeed found to inhibit aromatase activity in human trophoblasts,

(C) 2010 Society of Biological Psychiatry

Address correspondence to Anat Biegon, Ph.D., Bldg. 490 Medical, Upton, New York 11973. biegon@ bnl.gov. Authors AB and S-WK contributed equally to this work.

The authors report no biomedical financial interests or potential conflicts of interest. 
granulosa cells, and breast cancer cells, presumably through direct competitive binding to the active site of the enzyme $(7,8)$. This mechanism has not, to date, been demonstrated in neuronal tissues either in vitro or in vivo, although aromatase is expressed in the brain, and changes in brain aromatase activity have profound effects on behavior, cognition, and response to brain injury (10).

In the present study we implemented a newly developed method for the radiosynthesis of $\left[{ }^{11} \mathrm{C}\right]$ vorozole (11-13), a selective aromatase inhibitor that binds with high affinity to the active site of aromatase $(11,14,15)$, and used this tracer with positron emission tomography (PET) to test the possible interaction of nicotine with brain aromatase in female baboons in vivo.

\section{Methods and Materials}

\section{Animals}

The selective aromatase inhibitor $\left[{ }^{11} \mathrm{C}\right]$ vorozole was administered by IV injection to six female baboons (age range 14-20 years) from the Brookhaven National Laboratory colony. All of these animals had spontaneous estrus cycles, with estrus-the high-estrogen phasemanifested by marked peri-anal swelling and reddening. Animals were scheduled for experiments at least 2 weeks after estrus (i.e., in the follicular phase of the cycle when estrogen levels are low).

All experiments were approved by the Brookhaven Institutional Animal Care and Use Committee.

\section{Procedures}

Animals were anesthetized, injected with high specific activity $\left[{ }^{11} \mathrm{C}\right]$ vorozole and imaged with PET over a 90-min period as recently described (13). Each experimental day consisted of two radiotracer injections 2 hours apart. The second injection was preceded by an IV injection of nicotine $\left(.015\right.$ or $.03 \mathrm{mg} / \mathrm{kg}$ ) given $5 \mathrm{~min}$ before the $\left[{ }^{11} \mathrm{C}\right]$ vorozole. Blood samples for tracer determination were taken from all animals as described (13). In addition, blood samples for determination of nicotine and its major metabolite cotinine were obtained before and after nicotine injection from four baboons injected with the high $(.03 \mathrm{mg} / \mathrm{kg})$ dose of nicotine and two given the low dose $(.015 \mathrm{mg} / \mathrm{kg})$. Blood $(4 \mathrm{~mL})$ was withdrawn from the popliteal artery before nicotine administration and 2 min after nicotine administration, with additional samples taken $8,15,30,60$, or 90 min later. Plasma nicotine and cotinine analysis was performed in the Analytic Psychopharmacology Laboratories at the Nathan Kline Institute, Orangeburg, New York.

\section{Data Analysis}

Time frames were summed over the 90-min experimental period. The sum of PET frames from one baboon was coregistered with a three-dimensional magnetic resonance image of the same animal with PMOD (PMOD Technologies, Zurich, Switzerland). Regions of interest were placed over the amygdala, the preoptic area, striatum, cerebellum, cortical white matter, and whole brain on the summed image and then projected onto the dynamic images to obtain time activity curves. Regions occurring bilaterally were averaged. The dynamic data from nine studies (six regions in each) were analyzed graphically as well as by the one- and two-compartment model to derive kinetic constants and the total volume of distribution (VT), which is related to local enzyme availability (16). Statistical analysis of the results was performed by two-way analysis of variance followed by post hoc analyses with Fisher's Protected Least Significant Difference test and by paired $t$ test (two-tailed), with Statview software (College Station, Texas). 


\section{Results}

Injections of the radiotracer alone (baseline studies, $n=8$ ) resulted in a highly

heterogeneous distribution of radioactivity; with the highest levels found in the amygdala and preoptic area (Figure 1). Pretreatment with either a high $(.03 \mathrm{mg} / \mathrm{kg}, n=4)$ or a low (. $015 \mathrm{mg} / \mathrm{kg}, n=4)$ dose of nicotine administered IV $5 \mathrm{~min}$ before radiotracer injection resulted in a remarkable reduction of tracer uptake in the brain (Figure 1).

Results of the analysis of the time-activity curves in brain regions and plasma by the graphical approach $(\mathrm{GA}, 16)$ were compared with the results of applying the one- and twocompartment models ( $1 \mathrm{C}$ and $2 \mathrm{C}$, respectively). The correlation coefficient for $\mathrm{GA}$ and $2 \mathrm{C}$ was $R=.92$ (fit: GA=- $.042+1.02 \times 2 \mathrm{C}$ ), and the correlation and fit for GA and $1 \mathrm{C}$ was $R$ $=.702(\mathrm{GA}=.223+1.22 \times 1 \mathrm{C})$. Therefore, the 2 -compartment model agrees well with the graphical analysis that is model independent, and the 1-compartment model underestimates the GA distribution volume. Consequently, the kinetic parameters derived from the $2 \mathrm{C}$ model were used in the statistical analysis of the nicotine effects.

Analysis of variance of the VT revealed highly significant effects of region $[F(5)=4.23, p$ $<.002]$ and nicotine dose $[F(2)=6.6, p<.0025]$ and a nonsignificant region $\times$ dose interaction term $(p=.2)$. There were no effects on $\mathrm{K}_{1}$, the plasma-to-brain transfer term (data not shown). Regional, paired $t$ statistics were also used for comparing VT before and after nicotine treatment in the same animal and day. The results of this analysis (Figure 1) show that $.03 \mathrm{mg} / \mathrm{kg}$ nicotine produced a significant reduction in VT in the amygdala (39\%, $p<.015)$, preoptic area $(29 \%, p<.05)$, and striatum $(18 \%, p<.02)$, with nonsignificant trends in the same direction in cerebellum $(21 \%, p=.065)$, whole brain $(20 \%, p=.054)$, and cortical white matter $(10 \%, p=.075)$. In comparison, injection of a pharmacological dose of unlabeled vorozole (13) reduced VT by $57 \%, 41 \%$, and $21 \%$ in the amygdala, preoptic area, and cortical white matter, respectively (data not shown).

Two minutes after injection of nicotine ( $3 \mathrm{~min}$ before radiotracer injection), plasma levels ranged from $15.6 \mathrm{ng} / \mathrm{mL}$ (low dose) to $65 \mathrm{ng} / \mathrm{mL}$ (high dose, Figure 2). Nicotine levels declined exponentially with time (Figure 2). In parallel, plasma cotinine levels rose from $24-37.8 \mathrm{ng} / \mathrm{mL}$ at $2 \mathrm{~min}$ to $35-63 \mathrm{ng} / \mathrm{mL}$ at $90 \mathrm{~min}$ after nicotine injection.

\section{Discussion}

We show here for the first time that in vivo exposure to nicotine results in a significant and dose-dependent inhibition of $\left[{ }^{11} \mathrm{C}\right]$ vorozole binding in the female baboon brain. Both nicotine and vorozole inhibit aromatase activity by binding the active site of the enzyme, although the exact position and amino acid residues involved in the binding of nicotine have not been elucidated at the same level of detail as the interaction of vorozole $(7,15)$.

Therefore, the most likely explanation for the reduction in vorozole binding in the brain after nicotine injection is hindered access of vorozole to its binding site due to the occupation (or steric hindrance) of this site by nicotine. The size of the effect (more than 50\% of the maximal inhibition obtained with a blocking dose of vorozole) suggests that nicotine is capable of inhibiting the activity of aromatase in the primate brain.

The plasma nicotine concentrations found in our animals around the time of tracer injection were in the same range as those reported in plasma of people smoking low-, medium-, or high-nicotine cigarettes, which range from 5 to $63 \mathrm{ng} / \mathrm{mL}$ (17).

Although it seems that the passage of cotinine across the blood brain barrier is hindered relative to nicotine when it is injected in trace amounts in humans (18), cotinine can form in the brain itself and is found in rat brain after nicotine exposure (19). Like nicotine, cotinine 
does inhibit aromatase in vitro (7). Our results show that the levels of cotinine in plasma (and likely in the brain as well) are still increasing even $90 \mathrm{~min}$ after nicotine injection. Therefore, cotinine also probably plays a role in the inhibition of $\left[{ }^{11} \mathrm{C}\right]$ vorozole binding reported here and in the inhibition of aromatase activity in chronic smokers.

Inhibition of brain aromatase by nicotine and other constituents of tobacco might explain some of the behavioral sex differences reported in studies on the effects of cigarette smoking and nicotine in humans and experimental animals $(2,3)$. Nicotine was found to be less rewarding in women compared with men (2). In mice, ovariectomy completely abolished the rewarding properties of nicotine (3), and nicotine-evoked dopamine release from striatum was increased by estrogen in females and decreased by estrogen in males (20). These observations suggest that inhibition of brain aromatase activity and the subsequent decrease in estrogen levels might have opposite effects on the reward potential of nicotine in males and females, increasing reward in males and decreasing it in females. Furthermore, because brain aromatase is implicated in neuronal survival, cognition, mood, aggression, and sexual behavior (10), its inhibition by nicotine unveils a novel additional mechanism through which nicotine and cigarette smoking can exert their effects on behavior and neurophysiology. This mechanism merits consideration in future studies addressing the underlying reasons for cigarette smoking, its prevention, and treatment.

\section{Acknowledgments}

This study was carried out with the infrastructure of the Brookhaven National Laboratory under contract DEAC02-98CH10886. This work was supported in part by National Institutes of Health RO1 NS050285 (AB) and K05DA020001 (JSF).

\section{References}

1. Benowitz NL. Clinical pharmacology of nicotine: Implications for understanding, preventing, and treating tobacco addiction. Clin Pharmacol Ther. 2008; 83:531-534. [PubMed: 18305452]

2. Perkins KA, Donny E, Caggiula AR. Sex differences in nicotine effects and self-administration: Review of human and animal evidence. Nicotine Tob Res. 1999; 1:301-315. [PubMed: 11072427]

3. Torres OV, Natividad LA, Tejeda HA, Van Weelden SA, O'Dell L. Female rats display dosedependent differences to the rewarding and aversive effects of nicotine in an age-, hormone- and sex-dependent manner. Psychopharmacology. 2009; 206:303-312. [PubMed: 19629450]

4. Daniell HW. Osteoporosis and smoking. JAMA. 1972; 221:509. [PubMed: 5067964]

5. MacMahon B, Trichopoulos D, Cole P, Brown J. Cigarette smoking and urinary estrogens. N Engl J Med. 1982; 307:1062-1065. [PubMed: 7121516]

6. Nusbaum ML, Gordon M, Nusbaum D, McCarthy MA, Vasilakis D. Smoke alarm: A review of the clinical impact of smoking on women. Prim Care Update Ob Gyns. 2000; 7:207-214. [PubMed: 11025273]

7. Barbieri RL, Gochberg J, Ryan KJ. Nicotine, cotinine, and anabasine inhibit aromatase in human trophoblast in vitro. J Clin Invest. 1986; 77:1727-1733. [PubMed: 3711333]

8. Kadohama N, Shintani K, Osawa Y. Tobacco alkaloid derivatives as inhibitors of breast cancer aromatase. Cancer Lett. 1993; 75:175-182. [PubMed: 8313352]

9. Ghosh D, Griswold J, Erman M, Pangborn W. Structural basis for androgen specificity and oestrogen synthesis in human aromatase. Nature. 2009; 457:219-223. [PubMed: 19129847]

10. Roselli CE, Resko JA. Cytochrome P450 aromatase (CYP19) in the non-human primate brain: Distribution, regulation, and functional significance. J Steriod Biochem Mol Biol. 2001; 79:247253.

11. Lidstrom P, Bonasera TA, Kirilovas D, Lindblom B, Lu L, Bergstrom E, et al. Synthesis, in vivo rhesus monkey biodistribution and in vitro evaluation of a 11C-labelled potent aromatase inhibitor: [N-methyl-11C]vorozole. Nucl Med Biol. 1998; 25:497-501. [PubMed: 9720668] 
12. Takahashi K, Bergström M, Frändberg P, Vesström E-L, Watanabe Y, Långström B. Imaging of aromatase distribution in rat and rhesus monkey brains with [11C]vorozole. Nucl Med Biol. 2006; 33:599-605. [PubMed: 16843834]

13. Kim SW, Biegon A, Katsamanis ZE, Ehrlich CW, Hooker JM, Shea C, et al. Reinvestigation of the synthesis and evaluation of [N-methyl-(11)C]vorozole, a radiotracer targeting cytochrome P450 aromatase. Nucl Med Bio. 2009; 36:323-334. [PubMed: 19324278]

14. Wouters W, Snoeck E, De Coster R. Vorozole, a specific nonsteroidal aromatase inhibitor. Breast Cancer Res Treat. 1994; 30:89-94. [PubMed: 7726994]

15. Kao Y-C, Cam LL, Charles AL, Zhou D, Chen S. Binding characteristics of seven inhibitors of human aromatase: A site-directed mutagenesis study. Cancer Res. 1996; 56:3451-3460. [PubMed: 8758911]

16. Logan J. A review of graphical methods for tracer studies and strategies to reduce bias. Nucl Med Biol. 2003; 30:833-844. [PubMed: 14698787]

17. Russell MA, Wilson C, Patel UA, Feyerabend C, Cole PV. Plasma nicotine levels after smoking cigarettes with high, medium, and low nicotine yield. BMJ. 1975; 2:414-416. [PubMed: 1168517]

18. Halldin C, Någren K, Swahn CG, Långström B, Nybäck H. (S)-and (R)-[11C]nicotine and the metabolite (R/S)-[11C]cotinine. Preparation, metabolite studies and in vivo distribution in the human brain using PET. Int J Rad Appl Instrum B. 1992; 19:871-880. [PubMed: 1428915]

19. Crooks PA, Li M, Dwoskin LP. Metabolites of nicotine in rat brain after peripheral nicotine administration. Cotinine, nornicotine, and norcotinine. Drug Metab Dispos. 1997; 25:47-54. [PubMed: 9010629]

20. Dluzen DE, Anderson LI. Estrogen differentially modulates nicotine-evoked dopamine release from the striatum of male and female rats. Neurosci Lett. 1997; 230:140-142. [PubMed: 9259484] 


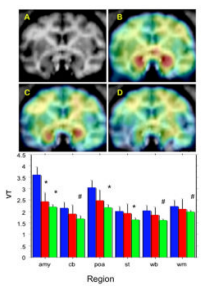

\section{Figure 1.}

Effect of nicotine pretreatment on brain aromatase Top: (A) baboon brain magnetic resonance imaging (MRI), coronal section at the level of amygdala. (B) Representative baseline positron emission tomography (PET) image coregistered with MRI. (C) The PET image of same baboon after low-dose nicotine $(.015 \mathrm{mg} / \mathrm{kg}$ ), coregistered with MRI. (D) The PET image after injection of high-dose $(.03 \mathrm{mg} / \mathrm{kg}$ ) nicotine, coregistered with MRI. The PET images show dose-corrected averaged frames acquired between 52.5 and 90 min after tracer injection, pseudocolored with the rainbow spectrum, with purple indicating the lowest density and red indicating the highest density of radioactivity. Bottom: paired studies (baseline followed by nicotine) were performed on the same day on four animals/nicotine dose. Bars represent mean \pm SEM of total volume of distribution (VT) at baseline (blue, $n=$ 8) or after a low dose (red, $n=4$ ) or high dose (green, $n=4$ ) of nicotine in amygdala (amy), cerebellum (cb), preoptic area (poa), striatum (st), whole brain (wb), and cortical white matter (wm). ${ }^{*} p<.05$. \#. $05<p<.1$; compared with baseline of same region/animal/day; paired $t$ test two-tailed. 


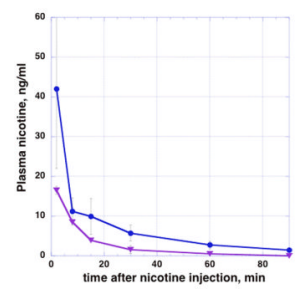

Figure 2.

Dose-related plasma levels of nicotine in female baboons. The circles (blue line) depictmeannicotine plasma levels in four animals injected with $.03 \mathrm{mg} / \mathrm{kg}$ nicotine IV. The triangles (purple line) depict nicotine levels in two animals injected with $.015 \mathrm{mg} / \mathrm{kg}$ nicotine. Error bars represent SD of 2-4 studies/time point. 